\title{
Editorial
}

\section{The General Neurotic Syndrome: A Re-Evaluation}

\author{
${\text { Peter } \text { Tyrer }^{\mathrm{a}} \text { Helen Tyrer }}^{\mathrm{a}}$ Boliang Guo ${ }^{\mathrm{b}}$

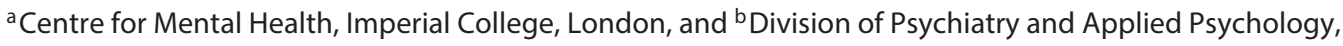 \\ School of Medicine, University of Nottingham, Nottingham, UK
}

The recent editorial on euthymia in Psychotherapy and Psychosomatics [1] emphasised the importance of the many subtle mood and functional states that are present in many people with mood disorders. These are often ignored in research studies, and any mood state that escapes formal diagnosis tends to be put into an undefined hinterland called euthymia. Many of these conditions are often hidden in short-term studies that use standard DSM criteria for diagnosis and wrongly assume that the absence of the relevant diagnosis constitutes 'recovery' [2]. It seldom does, and a longer longitudinal perspective shows a very different pattern. This pattern for many patients with anxiety and depressive disorders, the majority of whom probably have sufficient symptomatology and functional impairment to be referred to a psychiatrist, shows a fluctuating course in which the following features are almost always present: (i) varying degrees of anxiety and depression, with neither being absent entirely; (ii) the frequent co-occurrence of obsessive-compulsive, social phobic and agoraphobic symptoms manifested more frequently when the anxiety and depressive symptoms are more pronounced; (iii) prolonged periods of subthreshold depression and anxiety associated with impaired social function, and (iv) personality dysfunction within what is commonly known as the cluster $\mathrm{C}$ group (dependent, anankastic and avoidant/anxious) of personality disorders [3].

\section{KARGER}

E-Mail karger@karger.com

www.karger.com/pps
The presence of these features, often waxing and waning in response to life events, approximated closely the old diagnostic concept of neurosis and so was called the general neurotic syndrome $[4,5]$. This syndrome is defined as 'a persistent or relapsing disorder of combined anxiety and depressive symptoms (cothymia) associated with anxious, dependent and obsessional personality dysfunction, often interspersed with episodes of social anxiety, panic and somatoform symptoms'. The personality dysfunction is currently included under cluster $\mathrm{C}$ of personality disorders in the DSM classification, but in the new ICD-11 classification it would be described as mild or moderate personality disorder with negative affective-domain traits [6]. But when these articles were published they fell on somewhat stony ground. Although some people recognised the clinical validity of this concept (it was praised by Robert Kendell [7] in his Paul Hoch lecture to the American Psychiatric Association because it examined a spectrum rather than a single mood disorder), it was not taken up by others, apart from Gavin Andrews et al. [8], in Australia. It has to be remembered that this was the era in which nobody questioned the DSM classification. The DSM-III had just been published and the word 'neurosis', despite having been introduced by Cullen in Edinburgh as a neurological concept, had been imbued with too many additional meanings by psychoanalysis and the atheoretical ap- 
Table 1. The General Neurotic Syndrome Scale

\begin{tabular}{lccc}
\hline Positive characteristics & Score & Negative characteristics & Score \\
\hline $\begin{array}{l}\text { Simultaneous presence of syndromal anxiety and depressive } \\
\text { disorders (cothymia) }\end{array}$ & +2 & Persistent phobic and obsessional symptoms & -2 \\
$\begin{array}{l}\text { Variation in the primacy of depressive and anxiety symptoms at } \\
\text { different times }\end{array}$ & +3 & $\begin{array}{l}\text { Symptoms of anxiety and depression only } \\
\text { occur in response to immediate life events }\end{array}$ \\
\hline $\begin{array}{l}\text { If symptoms of panic, obsessive-compulsive disorder and } \\
\text { hypochondriasis are present they do not last longer than 3 months }\end{array}$ & +1 & +3 & Premorbid impulsive, borderline or \\
Premorbid anxious or dependent personality disorder & +1 & anti-social personality disorder \\
\hline $\begin{array}{l}\text { Premorbid anankastic (obsessive-compulsive) personality } \\
\text { disorder }\end{array}$ & +2 & \\
\hline $\begin{array}{l}\text { At least one parent has mixed anxiety depressive syndrome } \\
\text { (cothymia) }\end{array}$ & $0-3$ & $4-5$ \\
\hline $\begin{array}{l}\text { Total score (no general neurotic syndrome) } \\
\text { Total score (likely general neurotic syndrome) } \\
\text { Total score (definite general neurotic syndrome) }\end{array}$ & $\geq 6$ & \\
\hline
\end{tabular}

Because work has suggested that the negative scores are a little high, a score of 4 on the scale is now indicative of the syndrome.

proach that dominated the DSM-III could not allow neurosis to exist as a diagnostic term. Nonetheless, neurosis did creep into the DSM-III in the form of 'depressive neurosis', but the preferred synonym for this was the term of Akiskal [9], i.e. dysthymia or dysthymia disorder, which could allow the horrid word neurosis to be removed from circulation. Dysthymia was in some ways an unfortunate word as this could include much more than depression, and subsequently 'cothymia' was introduced to describe the simultaneous presence of concurrent anxiety and depressive disorders [10-12]. But of course the concept of neurosis did not disappear. In a memorable editorial in The Lancet, the anonymous contributor concluded that 'neurosis is not dead, it has merely retreated in disorder' [13].

Now that serious science is beginning to question the artificially discrete categories of the DSM classification, most formidably with the introduction of the Research Domain Criteria (RDoC), a broader system of classification which examines spectra of disorders [14], and also the new clinimetric approach [15], it is reasonable to resurrect the idea of the general neurotic syndrome.

\section{General Neurotic Syndrome Scale}

The full scale generated in 1983 is shown in table 1 . This had both negative and positive items, and scores of 4-6 were regarded as likely indices of the general neu- rotic syndrome $[5,9]$. In retrospect it was probably a mistake to give so much weight to the negative items in the scale, particularly the negative scoring of persistent phobic and obsessional symptoms, as these could be regarded as an extension of the spectrum of the general neurotic syndrome, and the emphasis on discrete types of personality dysfunction may have been overstated as subsequent evidence suggests that these change over time $[15,16]$ and are better encapsulated as a dimensional measure [17]. Despite these changes, there is increasing evidence that personality disturbance associated with negative emotionality or negative affectivity [the new (longer) term for neurotic personality] is more stable than other personality dimensions over time $[16,18]$.

\section{Current Study of the General Neurotic Syndrome}

We are currently carrying out a 30-year follow-up study (Nottingham Study of Neurotic Disorder) of a cohort of anxious and depressed patients originally seen in general practice psychiatric clinics (a population similar to those attending psychiatric outpatient facilities but at an earlier stage in the referral process) [19]. The main hypothesis at the outset was that those with a constellation of features consistent with the general neurotic syndrome would have a worse outcome in terms of frequency of relapse, social function, contact with psychiatric services, and mortality compared to those without the syndrome 
[5]. Assessments have been made at regular intervals over this long time period.

We currently have data over a 12 -year period. The findings at 2 years showed that general neurotic syndrome-positive patients had a worse outcome than those who were general neurotic syndrome-negative, with mean scores on the main outcome scale, i.e. the Comprehensive Psychopathological Rating Scale (CPRS) [20], some 6 points higher than for the general neurotic syndrome-negative group, and stepwise logistic regression showed general neurotic syndrome status to be one of the two most important outcome indicators [5]. After 5 years, the predictors of good and poor outcomes were analysed using polychotomous stepwise regression. Univariate analysis suggested that the presence of the general neurotic syndrome was one of six covariates of potential prognostic importance, and the final combined results of these analyses consequently showed that the odds of our poorer outcome in those with the general neurotic syndrome and personality disorder were 3.28 times greater than in the absence of these features, and much greater than for either alone [21].

At 12 years the differences were maintained. The score differences in the CPRS remained high [22] $(p=0.0002)$, social functioning as measured by the Social Functioning Questionnaire (SFQ) [23] was significantly worse in the general neurotic syndrome group $(\mathrm{p}=0.004)$, and the global outcome using a 5-point scale [22] was also worse $(\mathrm{p}=0.046)$. There were 17 deaths in the cohort, including 8 in the general neurotic syndrome-positive group, with no difference in age of death $(\mathrm{p}=0.896)$.

In our current 30 -year follow-up, we are finding some differences from the earlier times. Although there continue to be chronic sufferers, there are several with past persistent and chronic problems who have overcome these by using a combination of personality strengths and environmental changes following the principles of nidotherapy $[24,25]$ to offset the adverse effects of their past.

\section{Discussion}

The concept of neuroticism remains controversial but it is clear that, however it is described, it is a fundamental component of mood disorder. The General Neurotic Syndrome Scale attempts to combine both symptomatic and personality features in a unified description that should aid the clinician and researcher in understanding the longitudinal course of anxiety and depressive disorders. The results of the Nottingham study to date show that these conditions cannot be described adequately using current diagnostic labels.

Current diagnoses such as major depressive episode and generalised anxiety disorder are quite inadequate to fulfil the essential requirements of any diagnosis, i.e. the identification and demarcation of the syndromes, their separation from other, often related disorders, their likely progression in the short-term so that appropriate treatment can be given, and their long-term prognosis. As a consequence, we have had very poor reliability of the diagnosis in field trials, with $\kappa$ agreements of only 0.2 for both major depressive episode and generalised anxiety disorder [26]. In addition, there are very high levels of co-occurrence (inaccurately called comorbidity) with other syndromes, especially with social anxiety and phobic and obsessional conditions, and very little confidence in treatment selection. The long-term outcomes that have persistently shown the same results as the original paper by Eysenck [27], with about 30\% recovering, 35\% improving but not with any degree of confidence that this will be maintained and another $35 \%$ pursuing a relapsing and chronic course, with addition of social anxiety, obsessional and somatoform features at different times $[22,28]$.

By assessing both personality status and all clinical symptoms at the initial contact, as is necessary when using the General Neurotic Syndrome Scale, it is possible to create a more meaningful diagnosis and so enable a treatment strategy to be followed. This has already been illustrated by the results of the Nottingham study. Those with low psychopathology scores after 10 weeks remained well after 5 years [21], suggesting that these patients need not have much in the way of specific therapy and, despite their official diagnoses, should be regarded as adjustment reactions. On the other hand, those with high General Neurotic Syndrome Scale scores should be approached very differently and the therapist should anticipate a persistent or relapsing course. Care should be taken in prescribing drugs such as benzodiazepines, as these are much more likely to lead to pharmacological dependence in patients with obsessive-compulsive and dependent personality traits [29], and preference should be made for psychological treatments in which dependent traits in particular may aid the success of treatment [18].

There is also a strong argument for resurrecting the concept of the general neurotic syndrome in current classifications, especially since the DSM diagnosis of dysthymia has now been discarded in favour of 'persistent depressive disorder'. In practice, and this is reinforced by research data, dysthymia is a complex mix of anxiety, de- 
pression and personality disorder almost indistinguishable from the general neurotic syndrome [23]. The worse outcome in those with the general neurotic syndrome should not be regarded with fatalism; it is not a universal picture of gloom that is predestined or unavoidable. In our study, and indeed in most of psychiatric practice, no attempt was made to treat the personality aspects of the general neurotic syndrome, and this needs to change, as there are many treatments now available for all forms of personality disorder, however inchoate and complicated they may appear to be [30].

The results of this work reinforce and extend the principles behind the concept of euthymia [1]. The notion of recovery from mood disorders is not easy to define but what is clear is that such a state allows people to have mood changes in an appropriate context and at the same time the absence of mood changes does not necessary indicate wellness. There is considerable argument over the value of the concept of well-being as a public health measure [31] but it is not going to go away and, similarly, the notion of 'ill-being' encapsulated by the general neurotic syndrome is also going to persist, irrespectively of the rules of formal classification.
The linkage of a constellation of clinical symptoms and personality dysfunction seems to be important in psychiatric management and it is unfortunate that the abolition of axis II in the DSM classification, especially reserved for personality disorder, could make the joint diagnosis of personality and clinical dysfunction less likely [32]. If we ignore personality dysfunction in practice, we fail to identify the factors that may make the prognosis of mood disorders worse $[33,34]$ and consequently make poor judgements. In this context personality disorder may be viewed as a diathesis, which includes the concept of neuroticism, which makes those who suffer from it more vulnerable to all of the stresses of life and so tends to precipitate mental disorder at levels that would have no effect on other people [35-37].

But if we are aware of this predisposition from firsttime patients who present with mood disorders, whether with euthymia, cothymia or dysthymia, we can do much more to offset morbidity, and this opportunity needs to be grasped.

\section{Disclosure Statement}

None of the authors have any conflict of interests to declare.

\section{References}

1 Fava GA, Bech P: The concept of euthymia. Psychother Psychosom 2016;85:1-5.

2 Fava GA: Subclinical symptoms in mood disorders: pathophysiological and therapeutic implications. Psychol Med 1999;29:47-61

3 Reich J, Thompson WD: DSM-III personality disorder clusters in three generations. Br J Psychiatry 1987;150:471-475.

4 Tyrer P: Neurosis divisible? Lancet 1985;325: 685-688.

5 Tyrer P, Seivewright N, Ferguson B, Tyrer J: The general neurotic syndrome: a coaxial diagnosis of anxiety, depression and personality disorder. Acta Psychiatr Scand 1992;85:201206.

6 Tyrer P, Reed GM, Crawford M: Classification, assessment, prevalence, and effect of personality disorder. Lancet 2015;385:717-726.

7 Kendell RE: Clinical validity. Psychol Med 1989;19:45-55.

8 Andrews G, Stewart G, Morris-Yates A, Holt $P$, Henderson S: Evidence for a general neurotic syndrome. Br J Psychiatry 1990;157:612.

9 Akiskal HS: Dysthymic disorder: psychopathology of proposed chronic depressive subtypes. Am J Psychiatry 1983;140;11-20.

10 Tyrer P: Classification of Neurosis. Chichester, Wiley, 1989.
11 Tyrer P, Seivewright H, Simmonds S, Johnson T: Prospective studies of cothymia (mixed anxiety-depression): how do they inform clinical practice? Eur Arch Psychiatry Clin Neurosci 2001;251(suppl 2):53-56.

12 Tyrer P: The case for cothymia: mixed anxiety and depression as a single diagnosis. Br J Psychiatry 2001;179:191-193.

13 Goodbye neurosis? Lancet 1982;320:29.

14 Cuthbert BN, Insel TR: Toward the future of psychiatric diagnosis: the seven pillars of RDoC. BMC Med 2013;11:126.

15 Fava GA, Rafanelli C, Tomba E: The clinical process in psychiatry: a clinimetric approach. J Clin Psychiatry 2012;73:177-184.

16 Seivewright $H$, Tyrer P, Johnson T: Changes in personality status in neurotic disorder. Lancet 2002;359:2253-2254.

17 Hallquist MN, Lenzenweger MF: Identifying latent trajectories of personality disorder symptoms change: growth mixture modelling in the longitudinal study of personality disorders. J Abnorm Psychol 2015;122:138-155.

18 Tyrer H, Tyrer P, Barrett B: Influence of dependent personality on the outcome and service costs of health anxiety. Int J Soc Psychiatry 2013;59:274-280.
19 Tyrer P, Seivewright N, Murphy S, Ferguson B, Kingdon D, Brothwell J, Darling C, Barczak P, Gregory S, Johnson AL: The Nottingham Study of Neurotic Disorder: comparison of drug and psychological treatments. Lancet 1988;332:235-240.

20 Åsberg M, Montgomery SA, Perris C, Schalling D, Sedvall G: A comprehensive psychopathological rating scale. Acta Psychiatr Scand Suppl 1978;271:5-29.

21 Seivewright H, Tyrer P, Johnson T: Prediction of outcome in neurotic disorder: a five year prospective study. Psychol Med 1998;28: 1149-1157.

22 Tyrer P, Seivewright H, Johnson T: The Nottingham Study of Neurotic Disorder: predictors of 12-year outcome of dysthymic, panic and generalised anxiety disorder. Psychol Med 2004;34:1385-1394.

23 Tyrer P, Nur U, Crawford M, Karlsen S, McLean C, Rao B, Johnson T: The Social Functioning Questionnaire: a rapid and robust measure of perceived functioning. Int J Soc Psychiatry 2005;51:265-275.

24 Tyrer P: Nidotherapy: a new approach to the treatment of personality disorder. Acta Psychiat Scand 2002;105:469-471. 
25 Tyrer P, Sensky T, Mitchard S: The principles of nidotherapy in the treatment of persistent mental and personality disorders. Psychother Psychosom 2003;72:350-356.

26 Regier DA, Narrow WE, Clarke DE, Kraemer HC, Kuramoto SJ, Kuhl EA, Kupfer DJ: DSM5 field trials in the United States and Canada. 2. Test-retest reliability of selected categorical diagnoses. Am J Psychiatry 2013;170:59-70.

27 Eysenck HJ: The effects of psychotherapy: an evaluation. J Consult Psychol 1952;16:319324.

28 Tyrer P: Neurosis divisible? Lancet 1985;325: 685-688.

29 Tyrer P, Owen R, Dawling S: Gradual withdrawal of diazepam after long-term therapy. Lancet 1983;321:1402-1406.
30 Bateman AW, Gunderson J, Mulder R: Treatment of personality disorder. Lancet 2015; 385:735-743.

31 Mehta N, Davies SC: The importance of psychiatry in public mental health. Br J Psychiatry 2015;207:187-188.

32 Newton-Howes G, Mulder R, Tyrer P: Diagnostic neglect: the potential impact of losing a separate axis for personality disorder. $\mathrm{Br} \mathrm{J}$ Psychiatry 2015;206:355-356.

33 Skodol AE, Geier T, Grant BF, Hasin DS: Personality disorders and the persistence of anxiety disorders in a nationally representative sample. Depress Anxiety 2014;31:721-728.
34 Newton-Howes G, Tyrer P, Johnson T, Mulder R, Kool S, Dekker J, Schoevers R: Influence of personality on the outcome of treatment in depression: systematic review and meta-analysis. J Pers Disord 2014;28:577593.

35 Griffith JW, Zinbarg RE, Craske MG, Mineka S, Rose RD, Waters AM, Sutton JM: Neuroticisim as a common mechanism in the internalising disorders. Psychol Med 2010;40: 1125-1136.

36 Tyrer P: Personality diathesis explains the interrelationships between personality disorder and other mental conditions. World Psychiatry 2011;10:108-109.

37 Tyrer P: Personality dysfunction is the cause of recurrent non-cognitive mental disorder: a testable hypothesis. Personal Ment Health 2015;9:1-7. 